\title{
Research on Shipborne Helicopter Electric Rapid Secure Device: System Design, Modeling, and Simulation
}

\author{
Zhuxin Zhang ${ }^{1,2,3}$, Qian Liu ${ }^{1,2,4, *} \mathbb{C}$, Dingxuan Zhao ${ }^{1,2,4}$, Lixin Wang ${ }^{1,2,4}$ and Pengcheng Yang ${ }^{1,2,4} \mathbb{C}$ \\ 1 Research Center of Special Carrier Equipment of Yanshan University, Yanshan University, \\ Qinhuangdao 066004, China; zhzhxn@ysu.edu.cn (Z.Z.); zdx@ysu.edu.cn (D.Z.); \\ wlx@stumail.ysu.edu.cn (L.W.); 18827551270@163.com (P.Y.) \\ 2 Key Laboratory of Special Carrier Equipment of Hebei Province, Yanshan University, \\ Qinhuangdao 066004, China \\ 3 School of Vehicle and Energy, Yanshan University, Qinhuangdao 066004, China \\ 4 School of Mechanical Engineering, Yanshan University, Qinhuangdao 066004, China \\ * Correspondence: lq_ysu@stumail.ysu.edu.cn
}

check for updates

Citation: Zhang, Z.; Liu, Q.; Zhao, D.; Wang, L.; Yang, P. Research on Shipborne Helicopter Electric Rapid Secure Device: System Design, Modeling, and Simulation. Sensors 2022, 22, 1514. https://doi.org/ $10.3390 / \mathrm{s} 22041514$

Academic Editor: Sung-Bae Cho

Received: 10 January 2022

Accepted: 14 February 2022

Published: 15 February 2022

Publisher's Note: MDPI stays neutral with regard to jurisdictional claims in published maps and institutional affiliations.

Copyright: (C) 2022 by the authors. Licensee MDPI, Basel, Switzerland. This article is an open access article distributed under the terms and conditions of the Creative Commons Attribution (CC BY) license (https:// creativecommons.org/licenses/by/ $4.0 /)$.

\begin{abstract}
The research objective of this paper is to propose a new type of ERSD to solve the problem of the uncontrollable velocity of the claw in the current RSD. Firstly, the working characteristics of the RSD in ASIST are analyzed, and the design scheme of the transmission system of the ERSD is provided. The control system is designed by combining the vector control algorithm with the fuzzy adaptive PID control algorithm. On this basis, the trajectory planning of claw capture velocity is completed. Finally, the dynamics model of the transmission system of the ERSD is built by power bond graph theory, and the system simulation is carried out. The results show that the maximum capture time, velocity, and force were reduced by $47 \%, 53 \%$, and $80 \%$. In addition, when the ERSD is towing the helicopter, the mechanical claw can still provide good velocity tracking performance under a maximum interference load of $34,000 \mathrm{~N}$.
\end{abstract}

Keywords: Electric Rapid Secure Device; fuzzy control; landing assist system; power bond graph; shipborne helicopter

\section{Introduction}

Many shipborne helicopters landing assist systems have been proposed to solve the problem of shipborne helicopters landing safely on medium and small ships and to improve the attendance rate of the shipborne helicopter in bad sea conditions, including Harpoon Assist Landing System, Recovery Assist Secure and Traverse System, and Aircraft Ship Integrated Secure and Traverse System (ASIST) [1,2]. ASIST, as the third generation of shipborne helicopter landing assist system, is considered a direction for future development because of its brand new landing assist idea, simplified system configuration, and superior performance indicators.

The process of the shipborne helicopter landing on the ship with the help of ASIST can be divided into the following five stages: the helicopter approaches the ship, the helicopter hovers above the deck, the helicopter lands on the deck, the helicopter is captured and secured by ASIST, and the helicopter is towed to the designated position by ASIST. Many scholars have researched the above shipborne helicopter landing process in recent years. Among them, Zan [3] and Lee et al. [4] have studied the influence of rotor thrust and fuselage load in the approach process of the shipborne helicopter by taking the Sea King helicopter as an example. Colwell [5] analyzed the influence of ships on shipborne helicopters when they hover over the deck. Wall et al. [6] further studied the dynamics of the ship-helicopter-rotor system in the hovering stage. Li et al. [7] studied the process of the shipborne helicopter colliding with the deck while landing on the ship. Zhao et al. [8] evaluated the reliability of shipborne helicopter landing ships of ASIST. Wang et al. [9,10] 
studied ship-helicopter system dynamics after the shipborne helicopter landed under complex sea conditions. However, few people have explored the capture and towing operation of the shipborne helicopter after landing. More specifically, few people have paid attention to ASIST's problems of large impact force on shipborne helicopters during capture and complex towing steps during towing missions. These two problems are caused by the fact that ASIST's execution engine, Rapid Secure Device (RSD), uses a quantitative hydraulic pump and accumulator as its power source, making the claw's velocity uncontrollable [11-13].

We know that asynchronous motors have the advantages of high power density, high reliability, and high energy transmission efficiency [14,15]. Suppose the asynchronous motor is matched with a stable and reliable velocity regulation algorithm. In this case, we can use the asynchronous motor instead of the hydraulic pump and accumulator as the power source of the RSD to solve the above problems. Vector control frequency conversion technology, with its high control accuracy and good dynamic response characteristics, has become the preferred choice for the velocity regulation algorithm of asynchronous motor $[16,17]$. However, when the RSD is in actual operation, the axial load of the motor is constantly changing, which leads to significant changes in many parameters of the induction motor, such as resistance and inductance [18]. Moreover, the vector control algorithm and the traditional Proportion Integration Differentiation (PID) controller used with it mostly relies on the mathematical model of the motor, which makes it challenging to achieve a good velocity tracking effect in practical application [19]. With the development of intelligent control technology, many intelligent control algorithms have been designed and used for motor velocity control. The fuzzy control algorithm has become the research focus because it does not depend on an accurate model. At present, this control algorithm has been applied to permanent magnet synchronous motor and has achieved a good control effect $[20,21]$. If the fuzzy control algorithm and vector control algorithm are combined to design a suitable control system for the RSD, the problem of mechanical claw velocity control can be solved effectively. Liu et al. [22] proposed the realization scheme of this idea in the speed control of the asynchronous motor and proved its feasibility, which makes the above scenario possible.

In this paper, aiming at the problems existing in the capture and towing stages of the RSD, an implementation scheme of Electric Rapid Secure Device (ERSD) for shipborne helicopters is proposed for the first time. The ERSD selects an asynchronous motor as the power source and combines the vector control algorithm with the fuzzy adaptive PID (FAPID) control algorithm as a velocity tracking controller, making the velocity of the claw controllable. By planning the trajectory of the claw's capture velocity, the ERSD ensures the capture time and minimizes the impact force. In this paper, the dynamic model of the ERSD transmission system is established based on the power bond graph theory, and the system simulation is carried out. Compared with the RSD, the ERSD proposed in this paper can significantly reduce the capture time, lessen the capture impact force, and make the traction operation easier. The ERSD expands ASIST's range of applications to include small shipborne aircraft such as the Unmanned Aerial Vehicle (UAV) and improves the efficiency of ASIST's towing operations.

\section{RSD Working Characteristics}

\subsection{The Functional Principle of ASIST}

Figure 1 shows the functional principle of ASIST. The system is mainly composed of the shipborne part and the airborne part. The shipborne part includes cameras, main control device, towing device, RSD, and light indicator, and the airborne part includes probe rod device and laser target source. The functional principle of the system is as follows:

When the shipborne helicopter reaches the upper part of the ship's flight deck and is ready for the landing mission, the cameras installed on the deck collect the laser target source information of the helicopter. The camera calculates the helicopter's position in real time and transmits it to the main control device. The main control device provides the 
helicopterist with light indication information via the light indicator to guide the helicopter to the designated landing area. At the same time, the main control device drives the RSD to track the helicopter's position by controlling the towing device but always keeps it a certain safe distance from the helicopter. When the helicopter is in a suitable place, and the external environment allows, the helicopter begins to land. The towing device drives the RSD forward rapidly after the helicopter lands on the deck. When the RSD impacts the probe rod, the claw, mounted on the RSD, scans the capture range and captures the probe rod. Finally, the operator controls the RSD to tow the helicopter to the designated location or hangar. Figure 2 shows the working state of the helicopter's tracking, capture, and towing by the RSD and towing device.

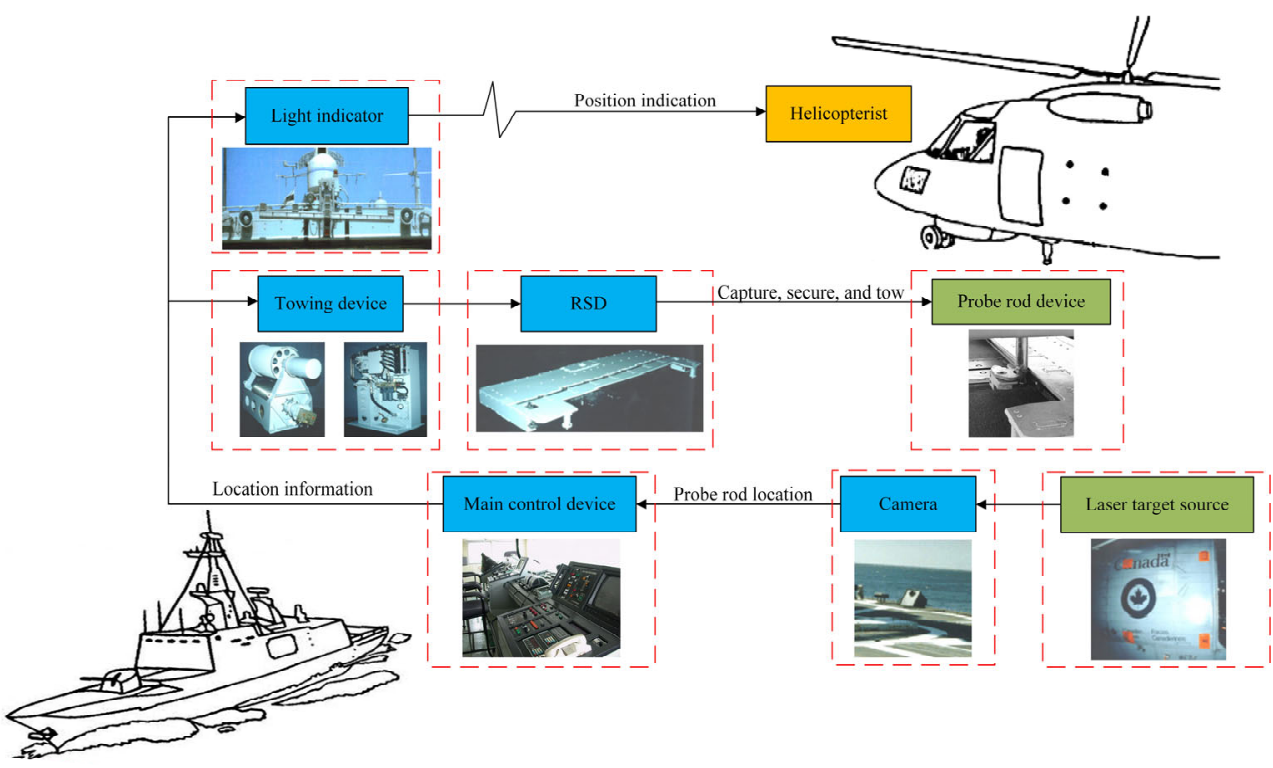

Figure 1. The functional principle of ASIST.

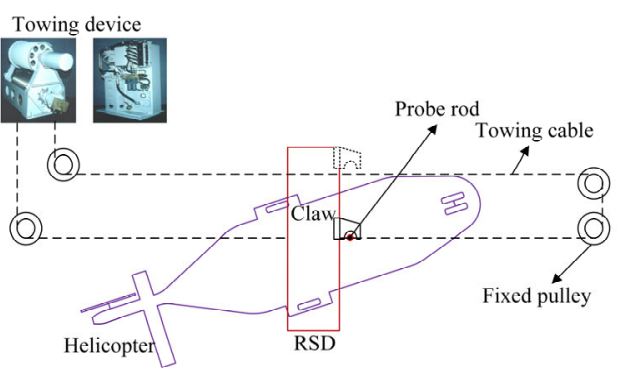

Capture state $(1.5 \mathrm{~s})$

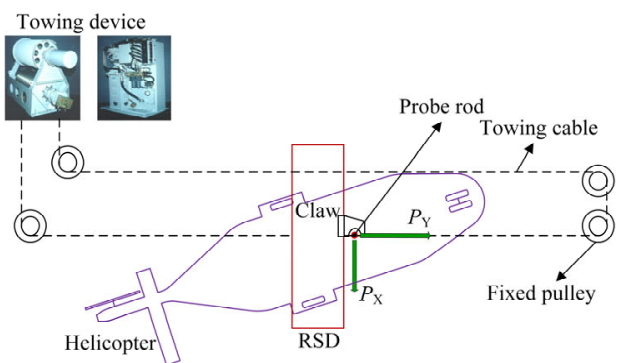

Towing state

Figure 2. The working state of RSD and towing device.

The system can capture shipborne helicopters in up to 7-level sea conditions. The whole process from the helicopter landing to the capture does not exceed $3 \mathrm{~s}$. In the second capture stage, that is, the mechanical claw of the RSD moves from the beginning to the successful capture of the probe rod; the maximum time required is not more than $1.5 \mathrm{~s}$. The system also allows helicopter towing operations in up to 3-level sea conditions. However, the execution-host (RSD) of the system is limited by technical requirements and space during the design, resulting in the following two complex problems in the execution of combat tasks:

1. When performing the shipborne helicopter capture mission, the RSD uses an accumulator as the power source to drive the claw movement through a hydraulic cylinder. In this process, the velocity of the claw is uncontrollable, which leads to 
a significant impact force of the claw on the probe rod. As shown in Figure 3, the impact force was measured as high as $5 \mathrm{kN}$. Therefore, ASIST cannot assist the landing of small shipborne aircraft such as the UAV, which significantly limits the scope of its application;

2. When performing the shipborne helicopter towing mission, the RSD uses a quantitative hydraulic pump as its power source, making the claw's velocity uncontrollable. As a result, the position of the shipborne helicopter needs to be adjusted repeatedly during the towing process. Moreover, the process is time-consuming, complicated, and requires highly experienced operators.

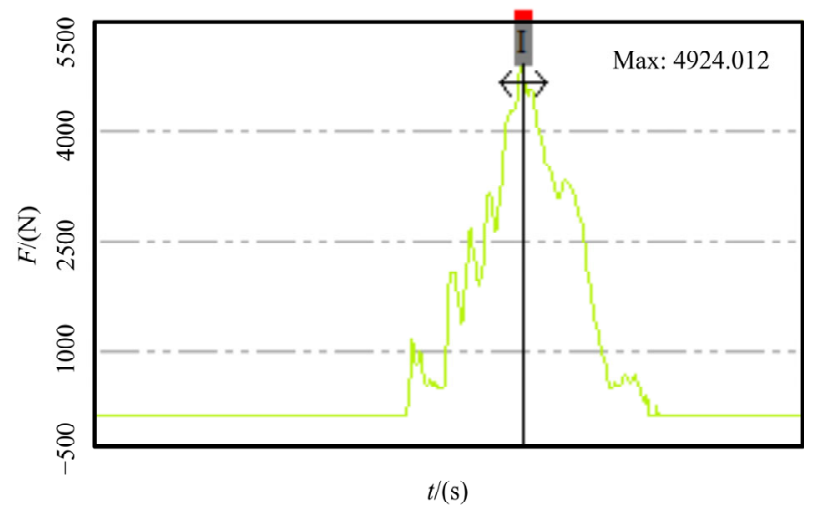

Figure 3. The force on the probe rod during capture.

\subsection{Force Analysis of RSD}

Before the new RSD design, it is necessary to analyze the related working characteristics of RSD. It can be seen from the functional principle of ASIST that the RSD mainly undertakes the following tasks:

1. After the helicopter lands, the RSD drives the mechanical claw to capture the probe rod within no more than $1.5 \mathrm{~s}$;

2. After capturing the probe rod, the RSD can reliably lock the helicopter by the claw under the condition of no more than 7-level sea conditions;

3. Under the condition of no more than 3-level sea conditions, the RSD and towing device work together to tow the helicopter to the designated position.

When the claw captures the probe rod at high velocity, the movement resistance of the claw is minimal and only comes from the inside of the RSD. When the RSD secures the helicopter or tows the helicopter, the claw bears a sizeable external load along the lateral direction.

Figure $4 \mathrm{a}$ shows the schematic diagram of the RSD working environment. Taking the center of the two rear wheels of the helicopter as the origin of the coordinates, the starboard direction of the ship as the $X$-axis forward direction, the bow direction as the $Y$-axis forward direction, and the upward direction along the plumb direction as the Z-axis forward direction, the spatial rectangular coordinate system is able to be established. When a ship is sailing on the sea, the flight deck will produce the following motions under the action of the ship's power system and waves: the yaw of translation along the $X$-axis, the pitch of translation along the $Y$-axis, the heave of translation along the $Z$-axis, the pitch of rotation around the $X$-axis, the roll of rotation around the $Y$-axis, and the bow roll of rotation around the $Z$-axis.

Figure $4 \mathrm{~b}$ shows the diagram of helicopter dynamics analysis. Assume that the helicopter's mass is $M_{\mathrm{H}}$ and the center of mass of the helicopter is $W_{\mathrm{H}}$, which is located on the central axis of the aircraft. Assume that the distance from the $Z$-axis is $L_{\mathrm{H}}$ and the height from the deck is $H$. Assume that the force point of the claw against the probe rod is $\mathrm{E}$, also located on the central axis of the aircraft, and the distance from the Z-axis is $L_{\mathrm{E}}$. The contact points between the three wheels and the deck are 1,2, and 3 . Assume that the 
distance between the centerline of the front wheelbase and rear-wheel is $L$, the distance between the two rear wheels is $B$, the maximum roll angle of the deck is $\theta$, the maximum transverse wind velocity is $V_{\mathrm{W}}$, the maximum lateral acceleration is $a_{\mathrm{X}}$, and the maximum vertical acceleration is $a_{\mathrm{Z}}$.

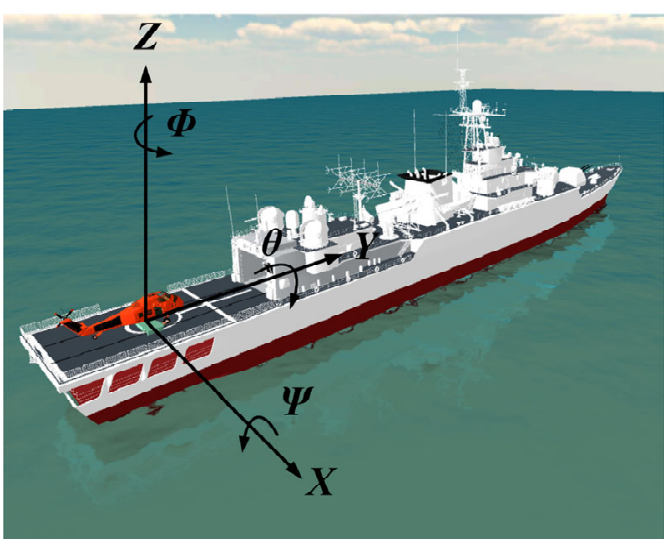

(a)

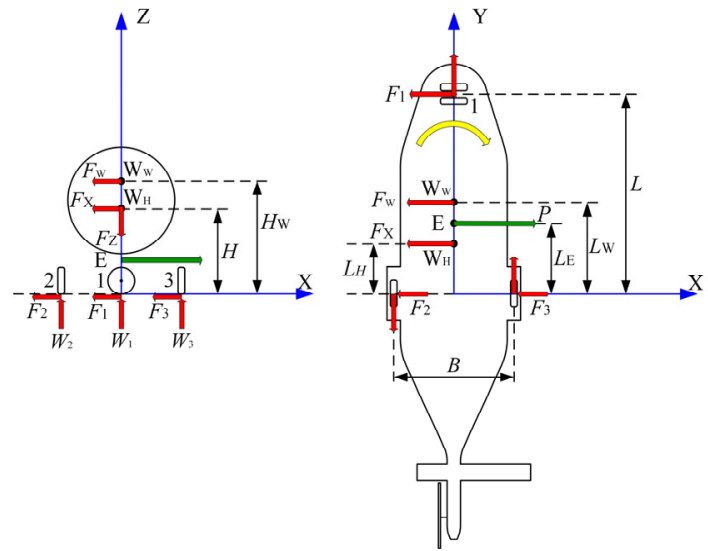

(b)

Figure 4. Model of helicopter and ship. (a) Six degrees of freedom motion of the ship; (b) the diagram of helicopter dynamics analysis.

Take the most extreme state to calculate the transverse load on the claw. Under the above rolling angle and acceleration, the thrust force of the RSD on the probe rod is $P$, and the universal axis of the front wheel is deflected $90^{\circ}$ to the state shown in Figure $4 \mathrm{~b}$. Under the action of thrust $P$, the helicopter rotates in the direction of the yellow arrow. In the calculation, it can be assumed that the ship deck is tilted in the negative direction of the $X$-axis, the maximum lateral acceleration is in the positive direction of the $X$-axis, and the maximum vertical acceleration is in the positive direction of the Z-axis.

Assume that when the sea breeze blows in the negative direction of the $X$-axis, the wind action center is $W_{\mathrm{W}}$, located on the central axis of the aircraft, the distance from Z-axis is $L_{\mathrm{W}}$, and the height from the deck is $H_{\mathrm{W}}$. In the transverse direction, the windward area is $A_{\mathrm{W}}$, the drag coefficient is $C_{\mathrm{W}}$, the air density is $\rho$, and the maximum wind velocity is $V_{\mathrm{W}}$.

The calculation formula of wind force is

$$
F_{\mathrm{W}}=\frac{1}{2} \rho C_{\mathrm{W}} A_{\mathrm{W}} V_{\mathrm{W}}^{2}
$$

where $A_{\mathrm{W}} \times C_{\mathrm{W}}=20$.

The forces acting on the center of mass $F_{X}$ and $F_{Z}$ are shown as follows:

$$
\left\{\begin{array}{l}
F_{\mathrm{X}}=M_{\mathrm{H}}\left(a_{x}+g \sin \theta\right) \\
F_{\mathrm{Z}}=M_{\mathrm{H}}\left(a_{z}+g \cos \theta\right)
\end{array} .\right.
$$

The vertical deck force acting on the front wheel can be calculated as

$$
W_{1}=\frac{F_{\mathrm{Z}} L_{\mathrm{H}}}{L} .
$$

The force balance in the Z-axis direction is

$$
F_{Z}-W_{1}-W_{2}-W_{3}=0
$$


Assume that the rolling friction coefficient of the aircraft wheel on deck is $f=0.02$, and the rolling resistance of the front wheel is

$$
F_{1 \mathrm{X}}=W_{1} f
$$

The sum of the rolling resistance of rear wheels is

$$
F_{2 Y}+F_{3 Y}=\left(W_{2}+W_{3}\right) f=\left(F_{Z}-W_{1}\right) f
$$

It can be obtained by taking the moment of the Z-axis, which is

$$
P=\frac{2\left(F_{\mathrm{W}} L_{\mathrm{W}}+F_{X} L_{\mathrm{H}}+F_{1 X} L\right)+\left(F_{2 Y}+F_{3 Y}\right) B}{2 L_{\mathrm{E}}} .
$$

Take a particular type of shipborne helicopter and ship as an example. Tables 1 and 2 list the related parameters.

Table 1. Parameters of the shipborne helicopter.

\begin{tabular}{cccc}
\hline Name of Parameters & Value & Name of Parameters & Value \\
\hline$L_{\mathrm{H}}$ & $0.9 \mathrm{~m}$ & $M_{\mathrm{H}}$ & $10,000 \mathrm{~kg}$ \\
$L_{\mathrm{E}}$ & $0.9 \mathrm{~m}$ & $L$ & $7 \mathrm{~m}$ \\
$B$ & $3.5 \mathrm{~m}$ & $H$ & $2 \mathrm{~m}$ \\
$L_{\mathrm{W}}$ & $0.9 \mathrm{~m}$ & $H_{\mathrm{W}}$ & $1.3 \mathrm{~m}$ \\
\hline
\end{tabular}

Table 2. Sea conditions table of the ship.

\begin{tabular}{ccc}
\hline Name of Parameters & 3-Level Sea Condition & 7-Level Sea Condition \\
\hline$\rho$ & $1.29 \mathrm{~kg} / \mathrm{m}^{3}$ & $1.29 \mathrm{~kg} / \mathrm{m}^{3}$ \\
$\theta$ & $10^{\circ}$ & $16^{\circ}$ \\
$a_{\mathrm{x}}$ & $1 \mathrm{~m} / \mathrm{s}^{2}$ & $2 \mathrm{~m} / \mathrm{s}^{2}$ \\
$a_{\mathrm{z}}$ & $2 \mathrm{~m} / \mathrm{s}^{2}$ & $4 \mathrm{~m} / \mathrm{s}^{2}$ \\
$V_{\mathrm{W}}$ & $12 \mathrm{~m} / \mathrm{s}$ & $30 \mathrm{~m} / \mathrm{s}$ \\
\hline
\end{tabular}

By substituting the data in Tables 1 and 2 into Equation (7), it can be obtained that the thrust required by the claw in 3-level sea conditions is $P_{1}=33,121 \mathrm{~N}$ and the securing force required by the claw in 7-level sea condition is $P_{2}=65,853 \mathrm{~N}$.

\section{Design of ERSD}

\subsection{Main Transmission System Design}

This paper proposes the ERSD transmission system schematic diagram based on the above working characteristics, as shown in Figure 5. The basic functional principle is as follows: when the ERSD performs the towing mission, the towing motor drives the movable pulley through the gearbox and ball screw and then transforms into the transverse motion of the claw through the chain drive mechanism. When the ERSD performs the capture mission, the capture motor directly drives the movable pulley through the ball screw, which is then converted to the transverse motion of the claw through the chain drive mechanism. In the process mentioned above, the working velocity of the two motors is controlled by a frequency converter and system controller. The parameters of the main components of the transmission system are shown in Table 3. The ERSD can also meet relevant performance requirements based on the above calculation results after checking. 


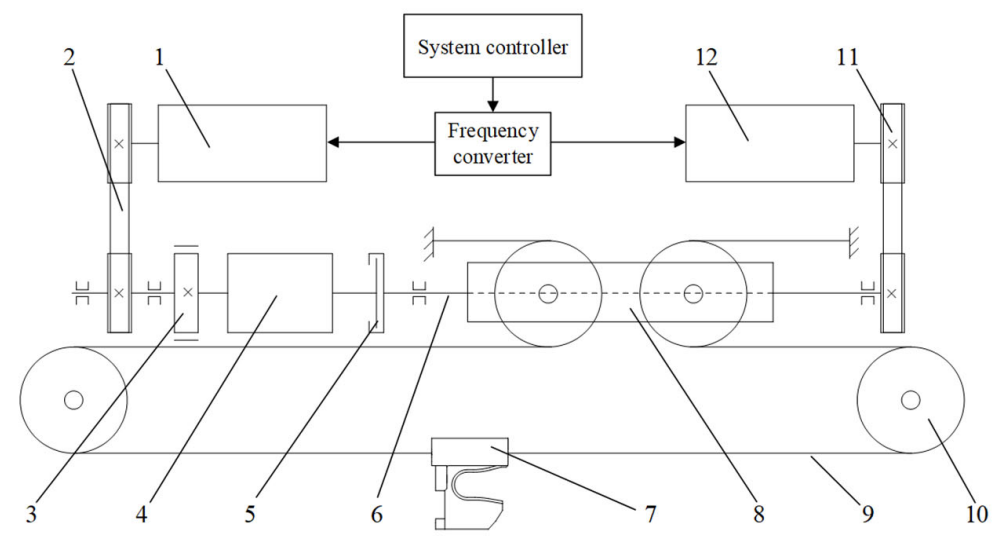

Figure 5. ERSD transmission system schematic diagram. The code names have the following meanings: 1-Towing motor, 2-Towing synchronous belt, 3-Brake, 4-Gearbox, 5-Clutch, 6-Ball screw, 7-Claw, 8-Movable pulley, 9-Chain, 10-Fixed pulley, 11-Capture synchronous belt, 12-Capture motor.

Table 3. The parameters of the transmission system.

\begin{tabular}{cccc}
\hline Name of Parameters & Value & Name of Parameters & Value \\
\hline Power of the asynchronous motor & $5 \mathrm{~kW}$ & Power of frequency converter & $5.5 \mathrm{~kW}$ \\
The reduction ratio of the gearbox & 40 & The lead of the ball screw & $20 \mathrm{~mm}$ \\
Friction torque of the brake & $30 \mathrm{~N} \cdot \mathrm{m}$ & Capture area width & $2000 \mathrm{~mm}$ \\
\hline
\end{tabular}

\subsection{Control System Design}

In this paper, fuzzy adaptive PID control algorithm and vector control frequency conversion algorithm are combined so that the control system can adjust the PID parameters in real time according to the field working state. Moreover, the asynchronous motor and claw would have better velocity tracking performance. The control system structure is shown in Figure 6.
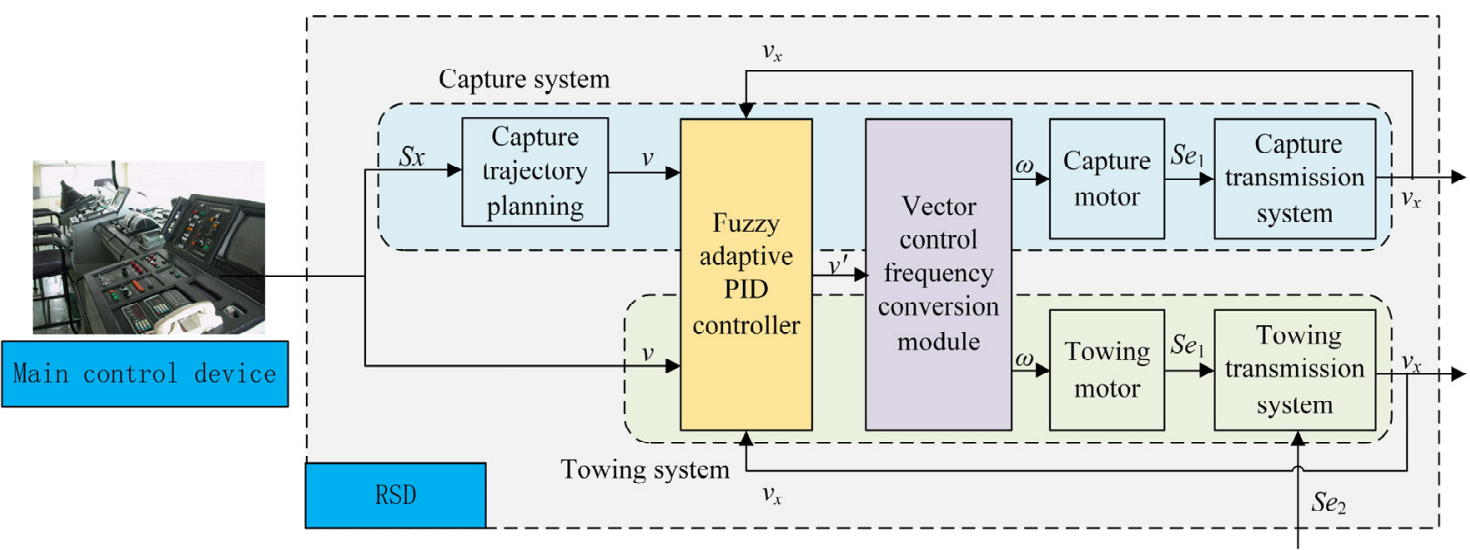

Figure 6. The control system structure.

\subsubsection{Vector Control Frequency Conversion Module}

As shown in Figure 7, the vector control frequency conversion module equates the current in the three-phase coordinate system of the asynchronous motor to the current in the two-phase static coordinate system. After coordinate transformation, the two-phase stationary coordinate system is equated to the two-phase synchronous rotating coordinate system. If the coordinate system is rotated with the core of the asynchronous motor simultaneously, the DC motor model is obtained. Then, the AC motor can be controlled in the same way as the DC motor [22]. 


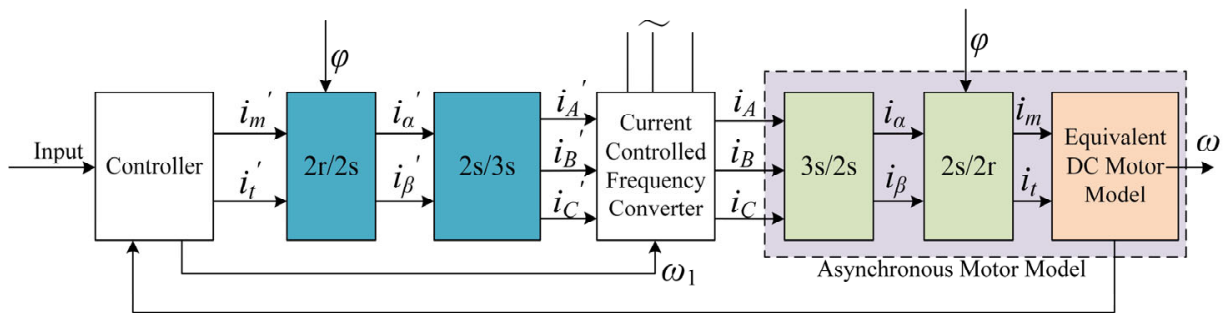

Figure 7. The principle of vector control [22].

The model of the asynchronous motor in a two-phase synchronous rotating coordinate system is given as follows:

$$
\begin{gathered}
{\left[\begin{array}{l}
u_{s d} \\
u_{s q} \\
u_{r d} \\
u_{r q}
\end{array}\right]=\left[\begin{array}{cccc}
R_{s}+L_{s} p & -\omega_{1} L_{s} & L_{m} p & -\omega_{1} L_{m} \\
\omega_{1} L_{s} & R_{s}+L_{s} p & \omega_{1} L_{m} & L_{m} p \\
L_{m} p & -\omega_{s} L_{m} & R_{r}+L_{r} p & -\omega_{s} L_{r} \\
\omega_{s} L_{m} & L_{m} p & \omega_{s} L_{r} & R_{r}+L_{r} p
\end{array}\right]\left[\begin{array}{l}
i_{s d} \\
i_{s q} \\
i_{r d} \\
i_{r q}
\end{array}\right],} \\
{\left[\begin{array}{l}
\psi_{s d} \\
\psi_{s q} \\
\psi_{r d} \\
\psi_{r q}
\end{array}\right]=\left[\begin{array}{cccc}
L_{s} & 0 & L_{m} & 0 \\
0 & L_{s} & 0 & L_{m} \\
L_{m} & 0 & L_{r} & 0 \\
0 & L_{m} & 0 & L_{r}
\end{array}\right]\left[\begin{array}{c}
i_{s d} \\
i_{s q} \\
i_{r d} \\
i_{s q}
\end{array}\right],} \\
T_{e}=n_{p} L_{m}\left(i_{s q} i_{r d}-i_{s d} i_{r q}\right), \\
T_{e}-T_{L}=p \omega J / n_{p}, \\
\omega=\omega_{1}-\omega_{s},
\end{gathered}
$$

where $\Psi_{s d}, \Psi_{s q}, \Psi_{r d}, \Psi_{r q}$ are stator flux and rotor flux, respectively; $i_{s d}, i_{s q}, i_{r d}, i_{r q}, u_{s d}, u_{s q}$, $u_{r d}, u_{r q}$ are stator current, stator voltage, rotor current, and rotor voltage, respectively; $R_{s}$, $R_{r}, L_{s}, L_{r}, L_{m}$ are stator resistance, stator inductance, rotor resistance, rotor inductance, and stator/rotor mutual inductance; $\omega_{1}$ is the angular velocity of the coordinate axis d-q relative to the stator; $\omega_{\mathrm{s}}$ is the angular velocity of the coordinate axis $\mathrm{d}-\mathrm{q}$ relative to the rotor; $\omega$ is the rotor angular velocity of the asynchronous motor; $n_{p}$ is the polar logarithm; $T_{L}$ is the load torque; $J$ is the moment of inertia of the motor; $p$ is the differential operator.

In Figure 7, if the two-phase rotation coordinate transformation, $2 \mathrm{r} / 2 \mathrm{~s}$, is offset with the $2 \mathrm{~s} / 2 \mathrm{r}$ transformation inside the asynchronous motor, and the two-phase to three-phase coordinate transformation, $2 \mathrm{~s} / 3 \mathrm{~s}$, is offset with the $3 \mathrm{~s} / 2 \mathrm{~s}$ transformation inside the asynchronous motor, then the lag effect of the inverter on the control signal can be ignored and the input control signal can be considered directly equivalent to the output frequency signal. Moreover, if the direction of the $d$-axis along the rotor total flux vector $\Psi_{r}$ is taken as the $M$-axis, and the $q$-axis rotated 90 degrees counterclockwise, which is perpendicular to the vector $\Psi_{r}$, is taken as the $T$-axis, then we get the following equation:

$$
\left\{\begin{array}{l}
\psi_{r m}=\psi_{r} \\
\psi_{r t}=0
\end{array} .\right.
$$

Substitute the above equation into the motor model to obtain

$$
\left\{\begin{array}{l}
\psi_{r}=\frac{L_{m}}{T_{r} p+1} i_{s m} \\
\omega_{s}=\omega_{1}-\omega=\frac{L_{m} i_{s t}}{T_{r} \psi_{r}} \\
T_{e}=\frac{n_{p} L_{m}}{L_{r}} i_{s t} \psi_{r}
\end{array}\right.
$$




\subsubsection{Fuzzy Adaptive PID Controller Design}

The fuzzy adaptive PID controller uses the fuzzy control principle to process the input error and the error change rate and obtain the correction signals of three parameters according to the fuzzy rule table defined by the controller. The correction signals are substituted into Equation (15) to calculate, and the adaptive setting PID parameters are obtained. The controller structure is shown in Figure 8 [22].

$$
\left\{\begin{array}{l}
k_{p}=k_{p}{ }^{\prime}+\Delta k_{p} \\
k_{i}=k_{i}^{\prime}+\Delta k_{i} \\
k_{d}=k_{d}{ }^{\prime}+\Delta k_{d}
\end{array}\right.
$$

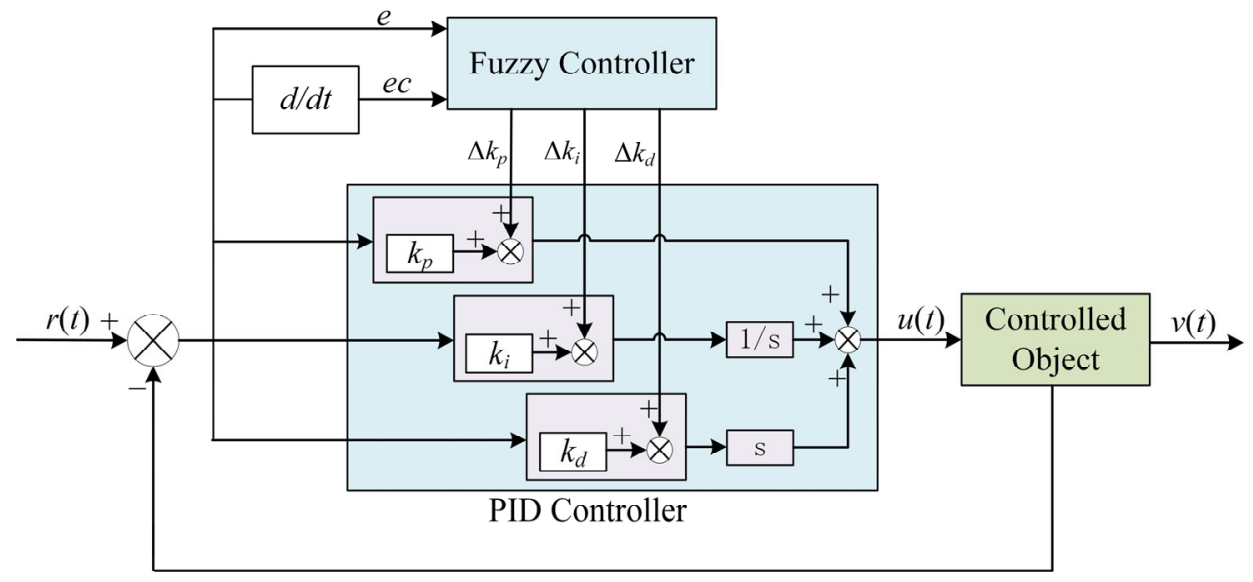

Figure 8. Block diagram of the fuzzy adaptive PID controller [22,23].

\subsection{The Capture Trajectory Planning}

According to the above working characteristics of the ERSD, the ERSD requires the velocity curve of the claw to meet the following requirements when performing capture mission:

- The total capture time should be as short as possible, and the maximum capture range should not be less than $2000 \mathrm{~mm}$;

- The velocity changes as smoothly as possible during the capture process;

- When the claw captures the probe rod, the impact force does not exceed $1000 \mathrm{~N}$. (The experimental results show that the allowable capture velocity is approximately $0.8 \mathrm{~m} / \mathrm{s}$ ).

The capture mission of the ERSD can be described as follows: for a fixed capture range, the claw first starts at a velocity $v_{1}$ and accelerates flexibly to a velocity $v_{\max }$ within a certain period, and then runs at that velocity uniformly for a while. When the claw approaches the probe rod, it enters the deceleration stage and decelerates to $v_{2}$ in the remaining distance. At the same time, it reaches the end of the capture range. In this paper, the trigonometric function curve is used to construct the velocity track of the claw [24]. Moreover, the curve is built by taking advantage of the infinite continuous differentiable cosine function, as shown in Figure 9.

The velocity-time function of the addition (decrement) velocity segment in Figure 9 is

$$
v(t)=v_{1}+\frac{1}{2}\left(v_{\max }-v_{1}\right)\left[1+\cos \left(\frac{t \pi}{t_{\mathrm{m}}}+\pi\right)\right],
$$

where $t$ is the time variable and $t_{\mathrm{m}}$ is the time required for the acceleration (deceleration) phase. 


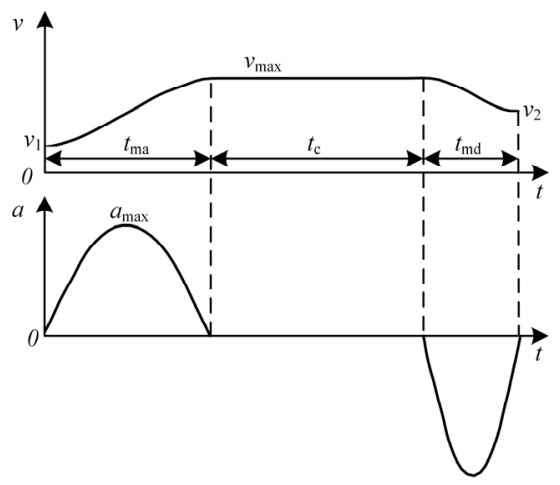

Figure 9. The velocity and acceleration curves.

After simplification, we can obtain

$$
v(t)=\frac{1}{2}\left(v_{\max }+v_{1}\right)-\frac{1}{2}\left(v_{\max }-v_{1}\right) \cos t^{\prime},
$$

where $t^{\prime}=\left(t / t_{m}\right) \pi$ and the velocity curve can be determined by selecting $t_{\mathrm{m}}$.

When the ERSD captures the helicopter probe rod, the capture range is generally divided into the close range, the mid range, and the far range according to the different positions of the probe rod. The velocity curves of the claws are also adjusted differently for different capture ranges.

1. The far range

When the position of the probe rod in the capture range is $S_{\mathrm{x}}>1300 \mathrm{~mm}$ when the helicopter lands, it is defined as the far range. According to the constructor of Equation (17) above, the trajectory planning curves of each section are as follows.

$$
\begin{cases}v_{\mathrm{a}}(t)=\frac{1}{2}\left(v_{\max }+v_{1}\right)-\frac{1}{2}\left(v_{\max }-v_{1}\right) \cos t^{\prime} \mathrm{a} & 0 \leq t<t_{\mathrm{m}} \\ v_{\mathrm{c}}(t)=v_{\mathrm{c}} & t_{\mathrm{m}} \leq t<t_{\mathrm{m}}+t_{\mathrm{c}} \\ v_{\mathrm{d}}(t)=\frac{1}{2}\left(v_{\max }+v_{2}\right)-\frac{1}{2}\left(v_{2}-v_{\max }\right) \cos t_{\mathrm{d}}^{\prime} & t_{\mathrm{m}}+t_{\mathrm{c}} \leq t\end{cases}
$$

where $v_{\mathrm{c}}$ and $t_{\mathrm{c}}$ are the velocity and time of uniform motion; $S_{\mathrm{a}}$ and $S_{\mathrm{d}}$ are acceleration distance and deceleration distance; $t_{a}^{\prime}=\left(t / t_{m}\right) \pi ; t_{d}^{\prime}=\left[\left(t-t_{m}-t_{c}\right) / t_{m}\right] \pi$; $t_{c}=\left(s_{x}-s_{a}-s_{d}\right) / v_{\max }$.

The starting velocity is $0.4 \mathrm{~m} / \mathrm{s}$, the capture velocity is $0.8 \mathrm{~m} / \mathrm{s}$, the maximum velocity is $3.6 \mathrm{~m} / \mathrm{s}$, and the acceleration/deceleration time is $0.3 \mathrm{~s}$. The calculated acceleration distance $S_{\mathrm{a}}=600 \mathrm{~mm}$, deceleration distance $S_{\mathrm{d}}=660 \mathrm{~mm}$. The minimum capture range is greater than the acceleration and deceleration distance, $S_{\mathrm{x}}>S_{\mathrm{a}}+S_{\mathrm{d}}$. Moreover, when the probe rod is at the farthest end, the whole capture time is $t=2 t_{\mathrm{m}}+t_{\mathrm{c}}=0.81 \mathrm{~s}$, which meets the capture time requirement.

\section{The mid range}

When the position of the probe rod in the capture range is $600 \mathrm{~mm}<S_{\mathrm{x}} \leq 1300 \mathrm{~mm}$ when the helicopter lands, it is defined as the mid range. At this time, the capture distance of the claw is relatively short, and the original velocity curve cannot meet the requirements of acceleration and deceleration distance in the minimum remote capture. Therefore, set the starting velocity at $0.4 \mathrm{~m} / \mathrm{s}$, the capture velocity at $0.8 \mathrm{~m} / \mathrm{s}$, the maximum velocity at $2.4 \mathrm{~m} / \mathrm{s}$, and the acceleration/deceleration time at $0.2 \mathrm{~s}$. After calculation, the whole capture time is $0.69 \mathrm{~s}$.

3. The close range

When the position of the probe rod in the capture range is $S_{\mathrm{x}} \leq 600 \mathrm{~mm}$ when the helicopter lands, it is defined as the close range. Because the probe rod is very close to 
the initial position, the claw does not need to accelerate to a high velocity to complete the capture mission in the specified time. Its velocity curve is Equation (19). Set the starting velocity at $0.4 \mathrm{~m} / \mathrm{s}$, capture and maximum at $0.8 \mathrm{~m} / \mathrm{s}$, and acceleration/deceleration time at $0.1 \mathrm{~s}$. After calculation, the whole capture time is $0.78 \mathrm{~s}$.

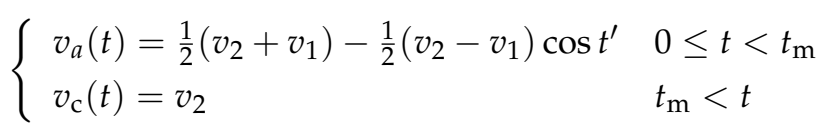

\section{System Modeling and Simulation}

\subsection{Dynamic Model of the Transmission System}

In this paper, the dynamics model of the ERSD transmission system is established through power bond graph theory [25], in which the energy transfer during the towing mission can be described by the following process:

- $\quad$ The driving torque of the towing motor $\left(S e_{1}\right)$ overcomes the rotational damping $\left(R_{3}\right)$ and drives the active belt wheel to rotate $\left(I_{2}\right)$;

- The active belt wheel drives the driven shaft, electromagnetic brake, and gearbox input shaft to overcome the rotational damping and rotate together $\left(I_{9}, R_{10}\right)$ through the synchronous belt $\left(\mathrm{TF}_{1}, \mathrm{TF}_{2}\right)$, during which the length of the synchronous belt will change with the change of the tension force on the belt $\left(C_{6}\right)$;

- After the gearbox $\left(\mathrm{TF}_{3}\right)$, the output shaft drives the clutch and ball screw to rotate together $\left(I_{13}, R_{14}\right)$;

- The screw transmission pair of the ball screw $\left(\mathrm{TF}_{4}\right)$ transforms the fixed axis rotation of the screw into the axial translation of the movable pulley $\left(I_{17}, R_{18}\right)$;

- Through pulley transmission $\left(\mathrm{TF}_{5}\right)$, the movable pulley drives the chain and claw to overcome friction damping and move laterally $\left(I_{23}, R_{24}\right)$; and the length of the chain also varies with the tension $\left(C_{21}\right)$;

- $\quad$ The probe road also applies an external load force to the claw $\left(S_{2}\right)$.

The system bond graph shown in Figure 10a can be drawn according to the above power flow analysis. Similarly, the capture system model is shown in Figure 10b.

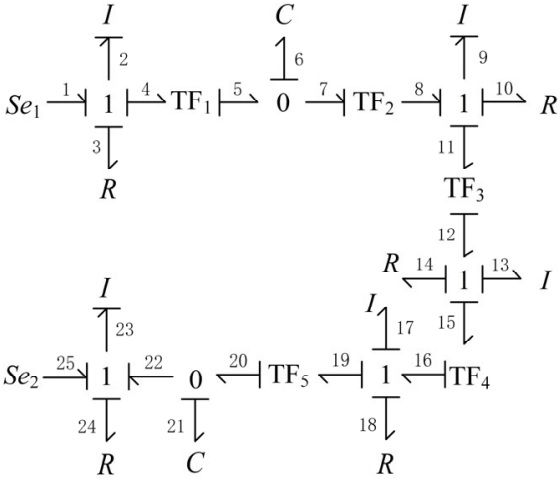

(a)

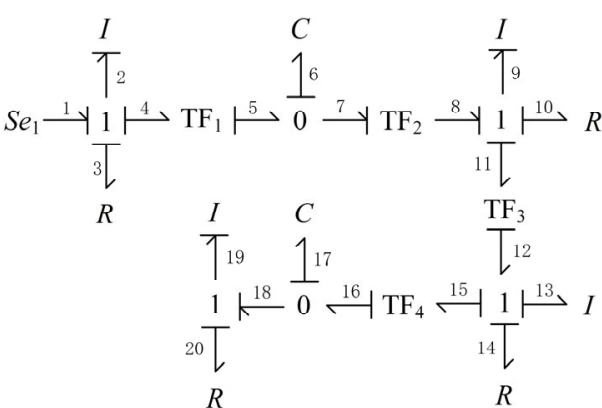

(b)

Figure 10. The system bond graph. (a) The towing system; (b) the capture system.

Taking the towing system as an example, the system state equation is expressed as follows:

$$
X^{\prime}{ }_{1}=A_{1} \cdot X_{1}+B_{1} \cdot U_{1} .
$$

The generalized momentum $p_{2}, p_{9}$, and $p_{23}$ correspond to the inertial elements $I_{2}, I_{9}$, and $I_{23}$ with integral causality. The generalized displacement $\mathrm{q} 6$ and $\mathrm{q} 21$, corresponding to 
the capacitive elements $C_{6}$ and $C_{21}$ with integral causality, were selected as the system's state variables. Its expression is as follows:

$$
X_{1}=\left[\begin{array}{lllll}
p_{2} & q_{6} & p_{9} & q_{21} & p_{23}
\end{array}\right]^{\mathrm{T}} .
$$

The input of the system includes $S e_{1}$ and $S e_{2}$, as shown below:

$$
U_{1}=\left[\begin{array}{ll}
S e_{1} & S e_{2}
\end{array}\right]^{T} .
$$

The relationships between generalized momentum and generalized displacement of energy storage elements $I_{2}, C_{6}, I_{9}, C_{21}$, and $I_{23}$ are shown as follows:

$$
\left\{\begin{array}{l}
f_{2}=\frac{1}{I_{2}} p_{2} \\
e_{6}=\frac{1}{C_{6}} q_{6} \\
f_{9}=\frac{1}{I_{9}} p_{9} \\
e_{21}=\frac{1}{C_{21}} q_{21} \\
f_{23}=\frac{1}{I_{23}} p_{23}
\end{array} .\right.
$$

The relationships between potential variables and flow variables of resistive elements $R_{3}, R_{10}, R_{14}, R_{18}$, and $R_{24}$ are shown as follows:

$$
\left\{\begin{array}{l}
e_{3}=R_{3} \cdot f_{3} \\
e_{10}=R_{10} \cdot f_{10} \\
e_{14}=R_{14} \cdot f_{14} \\
e_{18}=R_{18} \cdot f_{18} \\
e_{24}=R_{24} \cdot f_{24}
\end{array} .\right.
$$

The relationship between potential variables and flow variables of inertial elements $I_{13}$ and $I_{17}$ with differential causality is shown as follows:

$$
\left\{\begin{array}{l}
e_{13}=I_{13} \cdot f_{13}^{\prime} \\
e_{17}=I_{17} \cdot f_{17}^{\prime}
\end{array} .\right.
$$

The relationships between potential variables and flow variables of converters $\mathrm{TF}_{1}$, $\mathrm{TF}_{2}, \mathrm{TF}_{3}, \mathrm{TF}_{4}$, and $\mathrm{TF}_{5}$ are shown as follows:

$$
\begin{gathered}
\left\{\begin{array}{l}
e_{4}=\frac{1}{m_{1}} \cdot e_{5} \\
f_{5}=\frac{1}{m_{1}} \cdot f_{4}
\end{array},\right. \\
\left\{\begin{array}{l}
e_{8}=m_{2} \cdot e_{7} \\
f_{7}=m_{2} \cdot f_{8}
\end{array},\right. \\
\left\{\begin{array}{l}
e_{11}=\frac{1}{m_{3}} \cdot e_{12} \\
f_{12}=\frac{1}{m_{3}} \cdot f_{11}
\end{array},\right. \\
\left\{\begin{array}{l}
e_{15}=\frac{1}{m_{4}} \cdot e_{16} \\
f_{16}=\frac{1}{m_{4}} \cdot f_{15}
\end{array},\right. \\
\left\{\begin{array}{l}
e_{19}=\frac{1}{m_{5}} \cdot e_{20} \\
f_{20}=\frac{1}{m_{5}} \cdot f_{19}
\end{array} .\right.
\end{gathered}
$$


The relationships between potential variables and flow variables of each 0 knot and 1 knot are shown as follows:

$$
\begin{gathered}
\left\{\begin{array}{c}
e_{2}=S e_{1}-e_{3}-e_{4}, \\
f_{1}=f_{2}=f_{3}=f_{4}
\end{array},\right. \\
\left\{\begin{array}{l}
e_{5}=e_{6}=e_{7} \\
f_{6}=f_{5}-f_{7}
\end{array},\right. \\
\left\{\begin{array}{c}
e_{9}=e_{8}-e_{10}-e_{11} \\
f_{8}=f_{9}=f_{10}=f_{11}
\end{array},\right. \\
\left\{\begin{array}{l}
e_{12}=e_{13}+e_{14}+e_{15} \\
f_{12}=f_{13}=f_{14}=f_{15}
\end{array},\right. \\
\left\{\begin{array}{c}
e_{16}=e_{17}+e_{18}+e_{19} \\
f_{16}=f_{17}=f_{18}=f_{19}
\end{array},\right. \\
\left\{\begin{array}{l}
e_{20}=e_{21}=e_{22}, \\
f_{21}=f_{20}-f_{22} \\
e_{23}=e_{22}+S e_{2}-e_{24} \\
f_{22}=f_{23}=f_{24}
\end{array}\right.
\end{gathered}
$$

Combining Equations (23)-(37), the conservation equations of state variables can be obtained in the following form:

$$
\begin{gathered}
p_{2}^{\prime}=S e_{1}-\frac{R_{3}}{I_{2}} p_{2}-\frac{1}{m_{1} C_{6}} q_{6} \\
q_{6}^{\prime}=\frac{1}{m_{1} I_{2}} p_{2}-\frac{m_{2}}{I_{9}} p_{9} \\
p_{9}^{\prime}=\frac{m_{2} m_{3}^{2} m_{4}^{2} I_{9}}{C_{6}\left(m_{3}^{2} m_{4}^{2} I_{9}+m_{4}^{2} I_{13}+I_{17}\right)} q_{6}-\frac{R_{18}+m_{4}^{2} R_{14}+m_{3}^{2} m_{4}^{2} R_{10}}{m_{3}^{2} m_{4}^{2} I_{9}+m_{4}^{2} I_{13}+I_{17}} p_{9}-\frac{m_{3} m_{4} I_{9}}{m_{5} C_{21}\left(I_{17}+m_{3}^{2} m_{4}^{2} I_{9}+m_{4}^{2} I_{13}\right.} q_{21}, \\
q_{21}^{\prime}=\frac{1}{m_{3} m_{4} m_{5} I_{9}} p_{9}-\frac{1}{I_{23}} p_{23}, \\
p_{23}^{\prime}=S e_{2}+\frac{1}{C_{21}} q_{21}-\frac{R_{24}}{I_{23}} p_{23} .
\end{gathered}
$$

According to Equations (38)-(42), constant coefficient matrix $A_{1}$ and control matrix $B_{1}$ can be obtained in the following form:

$$
\begin{aligned}
& A_{1}=\left[\begin{array}{ccccc}
-\frac{R_{3}}{I_{2}} & -\frac{1}{m_{1} C_{6}} & 0 & 0 & 0 \\
\frac{1}{m_{1} I_{2}} & 0 & -\frac{m_{2}}{I_{9}} & 0 & 0 \\
0 & \frac{m_{2} m_{3}^{2} m_{4}^{2} I_{9}}{C_{6}\left(m_{3}^{2} m_{4}^{2} I_{9}+m_{4}^{2} I_{13}+I_{17}\right)} & -\frac{R_{18}+m_{4}^{2} R_{14}+m_{3}^{2} m_{4}^{2} R_{10}}{m_{3}^{2} m_{4}^{2} I_{9}+m_{4}^{2} I_{13}+I_{17}} & -\frac{m_{3} m_{4} I_{9}}{m_{5} C_{21}\left(I_{17}+m_{3}^{2} m_{4}^{2} I_{9}+m_{4}^{2} I_{13}\right.} & 0 \\
0 & 0 & \frac{1}{m_{3} m_{4} m_{5} I_{9}} & 0 & -\frac{1}{I_{23}} \\
0 & 0 & 0 & \frac{1}{C_{21}} & -\frac{R_{24}}{I_{23}}
\end{array}\right], \\
& B_{1}=\left[\begin{array}{ll}
1 & 0 \\
0 & 0 \\
0 & 0 \\
0 & 0 \\
0 & 1
\end{array}\right]
\end{aligned}
$$


Similarly, the capture system state equation is shown as follows:

$$
X^{\prime}{ }_{2}=A_{2} \cdot X_{2}+B_{2} \cdot U_{2} .
$$

The system state variables are expressed as follows:

$$
X_{2}=\left[\begin{array}{lllll}
p_{2} & q_{6} & p_{9} & q_{17} & p_{19}
\end{array}\right]^{\mathrm{T}} \text {. }
$$

The input of the system is only the output torque of the motor spindle $S e_{1}$, as shown below

$$
U_{2}=\left[S e_{1}\right] \text {. }
$$

Moreover, the constant coefficient matrix $A_{1}$ and control matrix $B_{1}$ can be obtained in the following form:

$$
\begin{gathered}
A_{2}=\left[\begin{array}{ccccc}
-\frac{R_{3}}{I_{2}} & -\frac{1}{m_{1} C_{6}} & 0 & 0 & 0 \\
\frac{1}{m_{1} I_{2}} & 0 & -\frac{m_{2}}{I_{9}} & 0 & 0 \\
0 & \frac{m_{2} m_{3}^{2} I_{9}}{C_{6}\left(m_{3}^{2} I_{9}+I_{13}\right)} & -\frac{m_{3}^{2} R_{10}+R_{14}}{m_{3}^{2} I_{9}+I_{13}} & -\frac{m_{3} I_{9}}{m_{4} C_{17}\left(m_{3}^{2} I_{9}+I_{13}\right)} & 0 \\
0 & 0 & \frac{1}{m_{3} m_{4} I_{9}} & 0 & -\frac{1}{I_{19}} \\
0 & 0 & 0 & \frac{1}{C_{17}} & -\frac{R_{20}}{I_{19}}
\end{array}\right], \\
B_{2}=\left[\begin{array}{ccccc}
1 & 0 & 0 & 0 & 0
\end{array}\right]^{\mathrm{T}} .
\end{gathered}
$$

\subsection{System Controllability Analysis}

The discriminant matrix $C_{\mathrm{d}}$ is introduced to judge the system controllability, as shown below:

$$
C_{\mathrm{d}}=\left[\begin{array}{lllll}
B & A B & A^{2} B & \cdots & A^{n-1} B
\end{array}\right],
$$

where $n$ is the dimension of state variable $X$. When the rank of $C_{d}$ is equal to $n$, the system is manageable.

According to Tables 4 and 5, calculate the $A_{1}, B_{1}, A_{2}$, and $B_{2}$ values and substitute them into Equation (50). It can be concluded that rank $\left(C_{\mathrm{d} 1}\right)=5$ and $\operatorname{rank}\left(C_{\mathrm{d} 2}\right)=5$, which indicates that the system can be controlled during the towing and capture mission.

\subsection{System Simulating}

The capture system simulation model and traction system simulation model were built to verify the feasibility of the ERSD transmission scheme and control system.

\section{Capture system simulation}

The positions of the probe road were set as $600 \mathrm{~mm}, 1300 \mathrm{~mm}$, and $2000 \mathrm{~mm}$, respectively, and the capture velocity curve was generated through the velocity trajectory planning module. Fuzzy adaptive PID controller and traditional PID controller are used as velocity controllers for simulation, respectively. The dynamics model parameters used in the simulation are shown in Table 4 . The total simulation time was set to $1 \mathrm{~s}$, and the acquisition velocity curve, displacement curve, and error curve of claw were obtained, as shown in Figures 11-13, respectively.

It is obvious from the figures that the claw can move along the input velocity curve, and the maximum capture time of the close and far range is approximately $0.8 \mathrm{~s}$, and the mid range is even reduced to $0.7 \mathrm{~s}$. In addition, the fuzzy adaptive PID controller has an obvious control effect in the motor acceleration stage, which makes the overshoot smaller and the acceleration more stable. However, the traditional PID controller has a violent shock in the motor acceleration stage and usually reaches a steady state after the motor starts at $0.1 \mathrm{~s}$. Moreover, the tracking error of the fuzzy adaptive PID controller is smaller in the constant speed stage. 


\section{Towing system simulation}

The given traction velocity is a sinusoidal curve with a maximum of $0.04 \mathrm{~m} / \mathrm{s}$, minimum of $0.02 \mathrm{~m} / \mathrm{s}$, and period of $2 \mathrm{~s}$. Meanwhile, with the help of the Uniform Random Number tool, the maximum Random interference load of 34,000 N is imposed. The dynamics model parameters used in the simulation are shown in Table 5. Set the total simulation time to $8 \mathrm{~s}$. The velocity tracking curve and the error curve of the claw are obtained, as shown in Figure 14.

Table 4. Parameters of the towing system.

\begin{tabular}{cccc}
\hline $\begin{array}{c}\text { Name of } \\
\text { Parameters }\end{array}$ & Value & $\begin{array}{c}\text { Name of } \\
\text { Parameters }\end{array}$ & Value \\
\hline$I_{2}$ & $1.04 \times 10^{-3} \mathrm{~kg} \cdot \mathrm{m}^{2}$ & $R_{14}$ & $2.5 \times 10^{-3} \mathrm{~N} \cdot \mathrm{m} /(\mathrm{rad} / \mathrm{s})$ \\
$R_{3}$ & $8.2 \times 10^{-4} \mathrm{~N} \cdot \mathrm{m} /(\mathrm{rad} / \mathrm{s})$ & $\mathrm{TF}_{4}\left(\mathrm{~m}_{4}\right)$ & $2 \pi /\left(20 \times 10^{-3}\right) \mathrm{rad} / \mathrm{m}$ \\
$\mathrm{TF}_{1}\left(\mathrm{~m}_{1}\right)$ & $1 / 48.51 \times 10^{-3} \mathrm{rad} / \mathrm{m}$ & $I_{17}$ & $35.753 \mathrm{~kg}$ \\
$C_{6}$ & $1 / 15,200 \mathrm{~m} / \mathrm{N}$ & $R_{18}$ & $40 \mathrm{~N} /(\mathrm{m} / \mathrm{s})$ \\
$\mathrm{TF}_{2}\left(\mathrm{~m}_{2}\right)$ & $48.51 \times 10^{-3} \mathrm{~m} / \mathrm{rad}$ & $\mathrm{TF}_{5}\left(\mathrm{~m}_{5}\right)$ & $1 / 2$ \\
$I_{9}$ & $3.865 \times 10^{-3} \mathrm{~kg} \cdot \mathrm{m}^{2}$ & $C_{21}$ & $0.5 \times 10^{-7} \mathrm{~m} / \mathrm{N}$ \\
$R_{10}$ & $3.8 \times 10^{-3} \mathrm{~N} \cdot \mathrm{m} /(\mathrm{rad} / \mathrm{s})$ & $I_{23}$ & $10,044.328 \mathrm{~kg}$ \\
$\mathrm{TF}_{3}\left(\mathrm{~m}_{3}\right)$ & 40 & $R_{24}$ & $30 \mathrm{~N} /(\mathrm{m} / \mathrm{s})$ \\
$I_{13}$ & $2.295 \times 10^{-2} \mathrm{~kg} \cdot \mathrm{m}^{2}$ & - & - \\
\hline
\end{tabular}

Table 5. Parameters of the capture system.

\begin{tabular}{cccc}
\hline $\begin{array}{c}\text { Name of } \\
\text { Parameters }\end{array}$ & Value & $\begin{array}{c}\text { Name of } \\
\text { Parameters }\end{array}$ & Value \\
\hline$I_{2}$ & $1.04 \times 10^{-3} \mathrm{~kg} \cdot \mathrm{m}^{2}$ & $\mathrm{TF}_{3}\left(\mathrm{~m}_{3}\right)$ & $2 \pi /\left(20 \times 10^{-3}\right) \mathrm{rad} / \mathrm{m}$ \\
$R_{3}$ & $8.2 \times 10^{-4} \mathrm{~N} \cdot \mathrm{m} /(\mathrm{rad} / \mathrm{s})$ & $I_{13}$ & $35.753 \mathrm{~kg}$ \\
$\mathrm{TF}_{1}\left(\mathrm{~m}_{1}\right)$ & $1 / 48.51 \times 10^{-3} \mathrm{rad} / \mathrm{m}$ & $R_{14}$ & $40 \mathrm{~N} /(\mathrm{m} / \mathrm{s})$ \\
$C_{6}$ & $1 / 15,200 \mathrm{~m} / \mathrm{N}$ & $\mathrm{TF}_{4}\left(\mathrm{~m}_{4}\right)$ & $1 / 2$ \\
$\mathrm{TF}_{2}\left(\mathrm{~m}_{2}\right)$ & $48.51 \times 10^{-3} \mathrm{~m} / \mathrm{rad}$ & $C_{17}$ & $0.5 \times 10^{-7} \mathrm{~m} / \mathrm{N}$ \\
$I_{9}$ & $9.22 \times 10^{-3} \mathrm{~kg} \cdot \mathrm{m}^{2}$ & $I_{19}$ & $44.328 \mathrm{~kg}$ \\
$R_{10}$ & $2 \times 10^{-3} \mathrm{~N} \cdot \mathrm{m} /(\mathrm{rad} / \mathrm{s})$ & $R_{20}$ & $30 \mathrm{~N} /(\mathrm{m} / \mathrm{s})$ \\
\hline
\end{tabular}

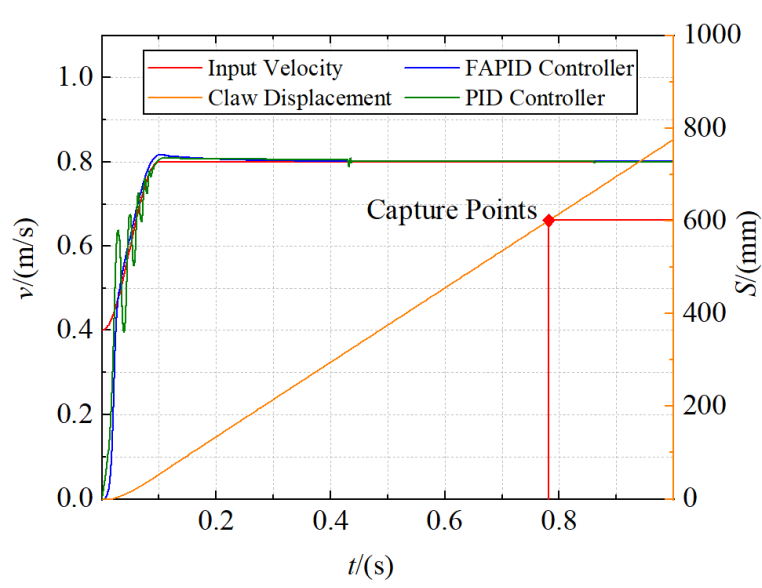

(a)

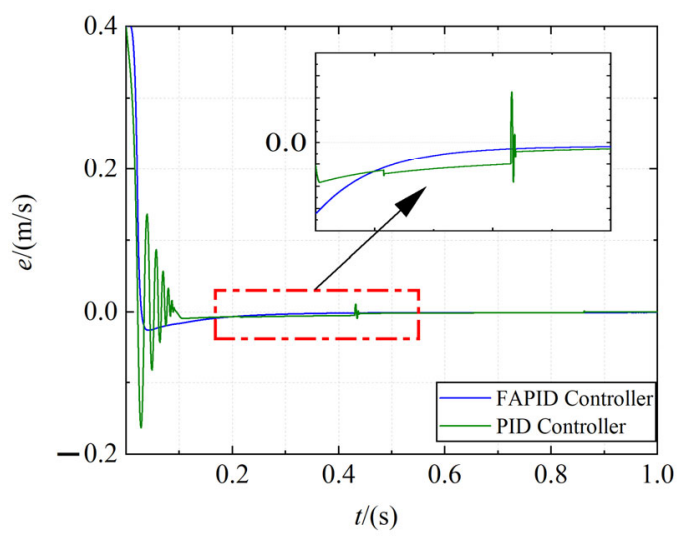

(b)

Figure 11. The capture curve of the close range $(600 \mathrm{~mm})$. (a) The velocity curve and displacement curve; (b) the error curve. 


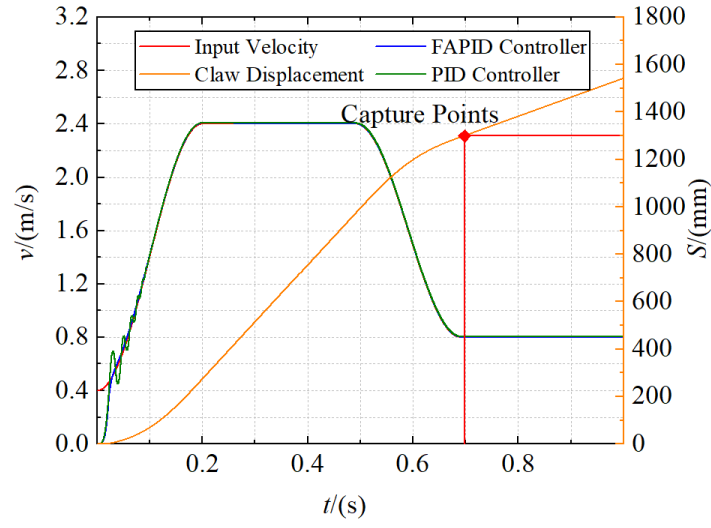

(a)

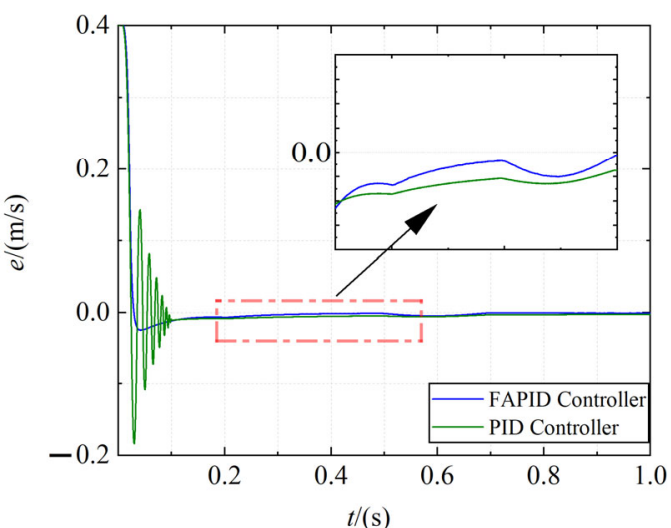

(b)

Figure 12. The capture curve of the mid range $(1300 \mathrm{~mm})$. (a) The velocity curve and displacement curve; (b) the error curve.

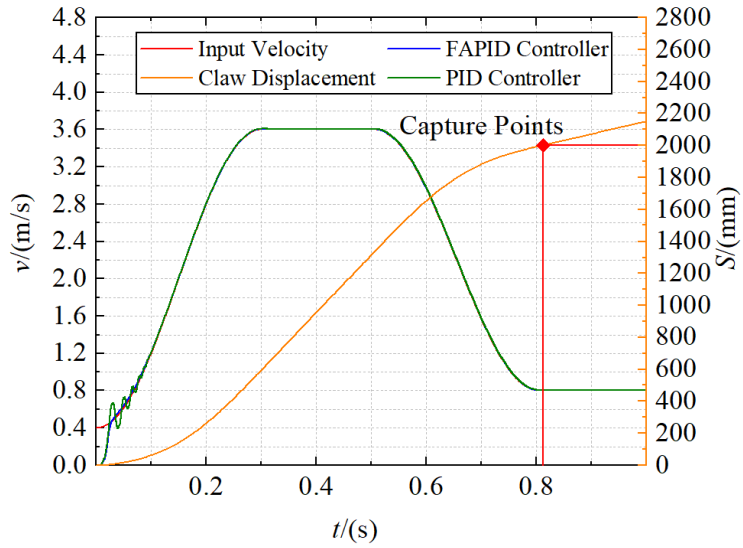

(a)

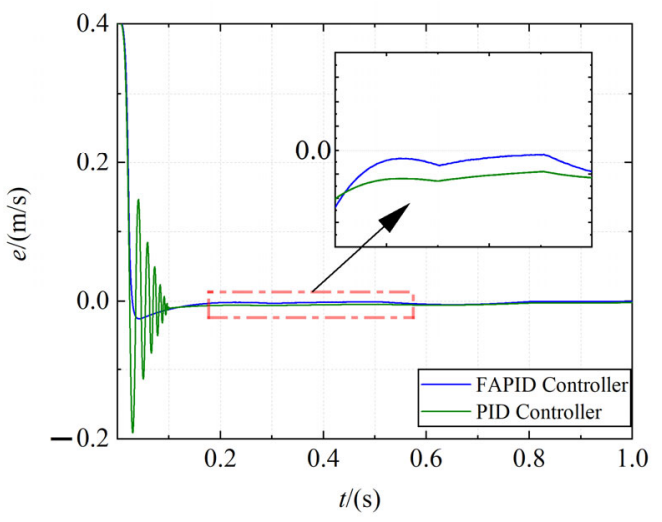

(b)

Figure 13. The capture curve of the far range $(2000 \mathrm{~mm})$. (a) The velocity curve and displacement curve; (b) the error curve.

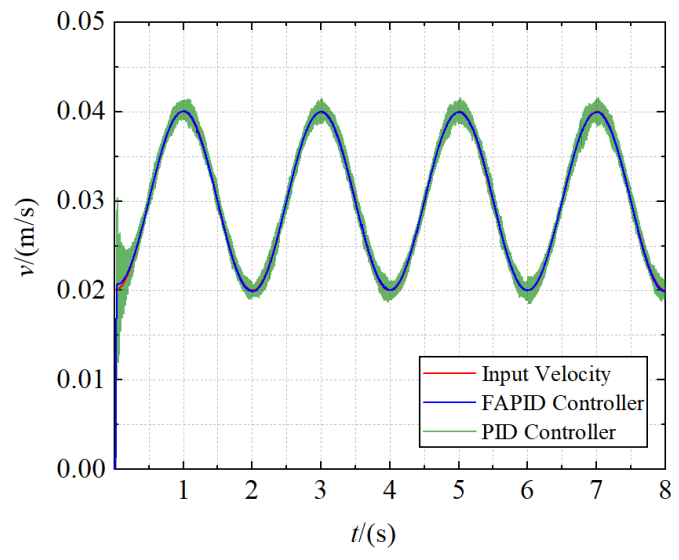

(a)

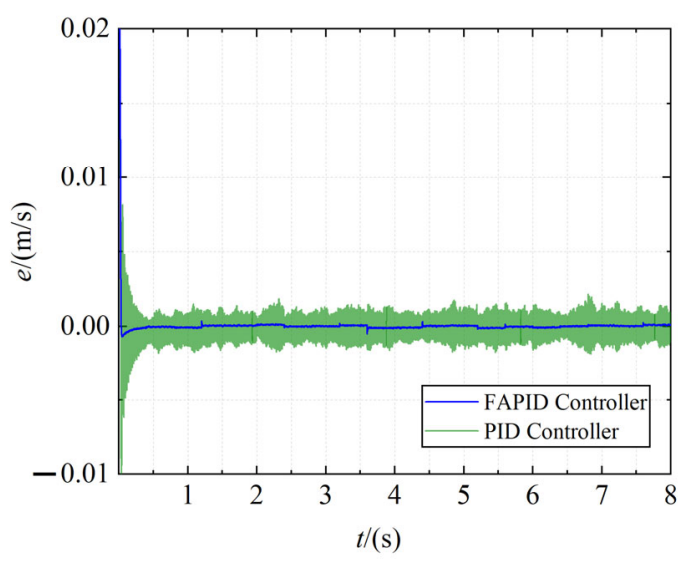

(b)

Figure 14. The towing curve. (a) The velocity tracking curve; (b) the error curve.

As shown in the figures, when a high random load is applied to the claw, the traditional PID controller is difficult to achieve a steady state in the motor acceleration stage and highfrequency clutter appears in the speed tracking stage. In contrast, the speed curve obtained 
using the fuzzy adaptive PID controller has good anti-interference ability, excellent dynamic response characteristics, and steady-state characteristics. It can meet the requirements of the ERSD when towing helicopters under high loads.

\section{Discussion}

In this paper, the working characteristics of the RSD are analyzed, and the implementation scheme of the ERSD transmission system is proposed. The capture velocity trajectory of the claw is designed, and the control system is created by combining vector control frequency conversion algorithm and fuzzy adaptive PID control algorithm. On this basis, the dynamics model of the transmission system of ERSD was built through power bond graph theory, and the controllability of the system was analyzed. The simulation test was carried out in MATLAB/Simulink. It can be seen from the simulation results that the ERSD proposed in this paper has the following significant characteristics:

1. As shown in Figure 15, based on meeting the functional requirements of the original RSD, the ERSD reduces the maximum capture time by approximately $47 \%$, the maximum capture velocity by approximately 53\%, and the capture impact force by approximately $80 \%$;

2. The claw can still have good velocity tracking performance under the maximum interference load of $34,000 \mathrm{~N}$.

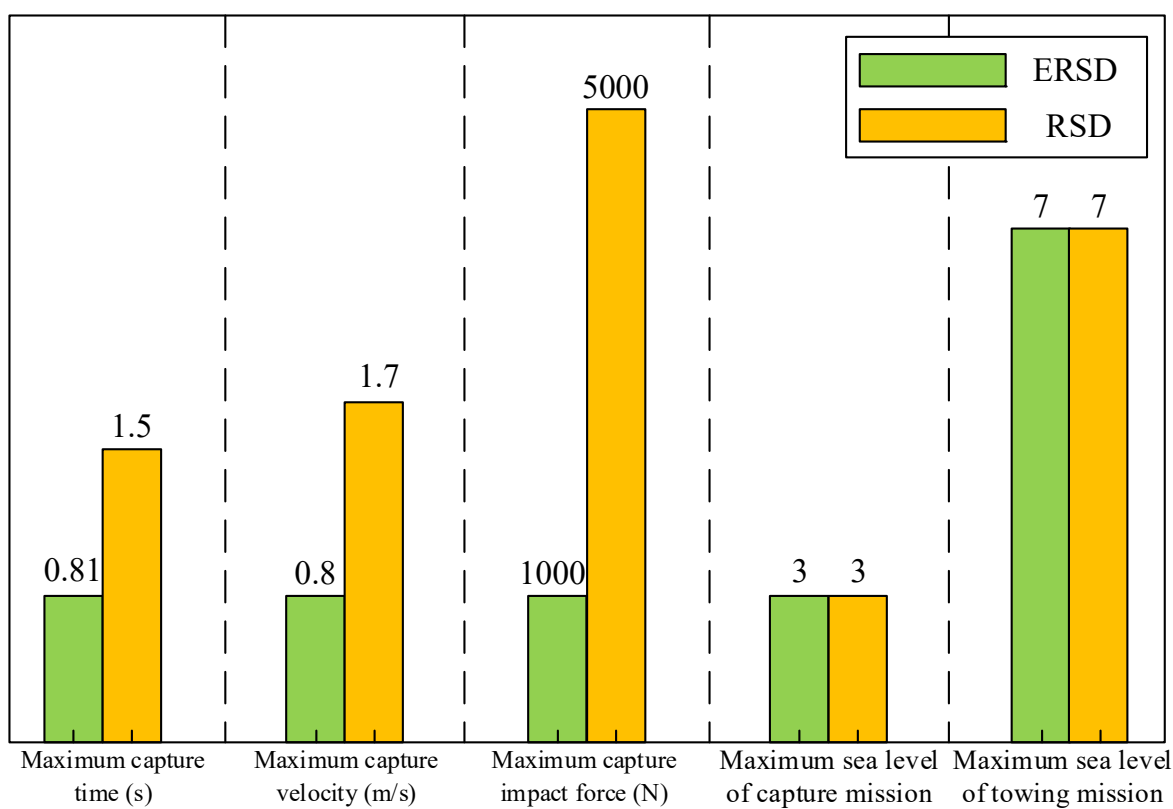

Figure 15. Comparison of operating parameters between RSD and ERSD.

The ERSD proposed in this paper enables ASIST to be compatible with small shipborne aircraft equipped with helicopter-like landing systems such as the UAV and improves the efficiency of ASIST towing operations. The research results obtained in this paper provide an essential basis for the subsequent production of ERSD and the design of an ASIST-based automatic traction system.

Author Contributions: Conceptualization, Z.Z. and Q.L.; methodology, Z.Z. and Q.L.; validation, Q.L. and L.W.; formal analysis, Q.L. and P.Y.; writing-original draft preparation, Q.L.; funding acquisition, Z.Z and D.Z. All authors have read and agreed to the published version of the manuscript.

Funding: This research was funded by Hebei Provincial Department of Science and Technology, grant number 20353501D and 21351802D, and Ministry of Science and Technology of China, grant number 2016YFC0802902.

Institutional Review Board Statement: Not applicable. 


\section{Informed Consent Statement: Not applicable.}

Conflicts of Interest: The authors declare no conflict of interest.

\section{References}

1. Chang, B.; Wang, H.; Yang, L. Status and development trends of the shipboard helicopters. Fligh. Dynam. 2016, 34, 7-12.

2. Liao, Z.; Lu, X.; Huang, Y.; Zhen, Z. Research progress of landing guidance and control for carrier-based helicopter. Trans. Nanjing. Univ. Aeronaut. Astronaut. 2018, 50, 745-753.

3. Zan, S.J. Experimental determination of rotor thrust in a ship airwake. J. Am. Helicopter. Soc. 2002, 47, 100-108. [CrossRef]

4. Lee, R.G.; Zan, S.J. Unsteady aerodynamic loading on a helicopter fuselage in a ship airwake. J. Am. Helicopter. Soc. 2004, 49, 149-159. [CrossRef]

5. Colwell, J.L. Effects of flight deck motion in high seas on the hovering maritime helicopter. In Proceedings of the 58th Annual Forum Proceedings-AHS International, Montréal, QC, Canada, 11-13 June 2002.

6. Wall, A.S.; Afagh, F.F.; Langlois, R.G.; Zan, S.J. Modeling helicopter blade sailing: Dynamic formulation and validation. J. Appl. Mech. 2008, 75, 61004-61014. [CrossRef]

7. Li, Y.; Zhang, Z.C.; Xiong, Z.; Xiao, J.X.; Li, G.H. Collision modeling method of ship-board helicopter landing. J. Syst. Eng. Electron. 2015, 430, 1691-1696.

8. Zhao, D.X.; Wang, Q.; Zhang, Z.X. Extenics theory for reliability assessment of carrier helicopter based on analytic hierarchy process. J. Jilin Univ. Eng. Tech. 2016, 46, 1528-1531.

9. Wang, Q.; Zhao, D.X.; Wei, H.L.; Zhao, Y. Study of the landing dynamics of carrier based helicopter under complex sea conditions. J. Northeast. Univ. Nat. Sci. 2017, 38, 1595-1600.

10. Wang, Q.; Zhao, D.X.; Zhao, Y.; Chen, N. Dynamic analysis of carrier helicopter on complex. J. Jilin Univ. Eng. Tech. 2017, 47, 1109-1113.

11. Salt, D. Electro-optic precision approach and landing system. In Proceedings of the Synthetic Vision for Vehicle Guidance and Control, Orlando, FL, USA, 17-18 April 1995.

12. Grant, L.J.V. Talon Hydraulic Helicopter/Shipboard Securing System. Nav. Eng. J. 1991, 103, 212-217. [CrossRef]

13. Linn, D.R.; Langlois, R.G. Development and experimental validation of a shipboard helicopter on-deck maneuvering simulation. J. Aircr. 2006, 43, 895-906. [CrossRef]

14. Boukhalfa, G.; Belkacem, S.; Chikhi, A.; Benaggoune, S. Genetic algorithm and particle swarm optimization tuned fuzzy PID controller on direct torque control of dual star induction motor. J. Cent. South. Univ. 2019, 26, 1886-1896. [CrossRef]

15. Qi, X.; Su, T.; Zhou, K.; Yang, J.; Gan, X.; Zhang, Y. Development of ac motor model predictive control strategy: An overview. P. CSEE 2021, 41, 6408-6418.

16. He, H.C.; Sun, L.; Zhang, Y.F. Asynchronous motor active disturbance rejection control based on vector control. Electr. Mach. Contrl. 2019, 31, 120-125.

17. He, H.C.; Sun, L.; Zhang, Y.F.; Zhou, Q. Research of sensorless vector control performance for induction motor at very low-speed and zero-speed. P. CSEE 2019, 39, 6095-6103+6190.

18. Lei, A.; Song, C.X.; Lei, Y.L.; Yao, F. Design Optimization of vehicle asynchronous motors based on fractional harmonic response analysis. Mech. Sci. 2021, 12, 689-700. [CrossRef]

19. Xia, C.Y.; Yu, J.L.; Tian, C.Y.; Hou, X.X. Slip frequency type vector control for brushless doubly-fed machine. Control. Decis. 2019, 34, 649-654.

20. Li, Y.; Qin, Y.; Zhou, Y.; Zhao, C. Model predictive torque control for permanent magnet synchronous motor based on dynamic finite-control-set using fuzzy control. Energy Rep. 2020, 6, 128-133. [CrossRef]

21. Zhao, X.M.; Wang, H.L.; Zhu, W.B. Feedback linearization control of permanent magnet linear synchronous motor based on adaptive fuzzy controller and nonlinear disturbance observer. Control Theory A 2021, 38, 595-602.

22. Liu, Q.; Zhang, Z.; Zhao, D.; Wang, L.; Meng, F.; Liu, C. Research on Speed Tracking of Asynchronous Motor Based on Fuzzy Control and Vector Control. In Proceedings of the 2020 39th Chinese Control Conference (CCC), Shenyang, China, 27-29 July 2020.

23. Tipsuwanpom, R.; Runghimmawan, T.; Intajag, S.; Krongratana, V. Fuzzy logic PID controller based on FPGA for process control. In Proceedings of the 2004 IEEE International Symposium on Industrial Electronics, Ajaccio, France, 4-7 May 2004.

24. Guo, X.G.; Li, C.X. A new flexible acceleration and deceleration algorithm. J. Shanghai Jiaotong Univ. 2003, 2, 205-207+212.

25. Aftabi Talami, M.; Jamali, A.; Nariman-zadeh, N. A new method for extracting the state equations from bond graph of dynamical systems (SEBG method). J. Gen. Syst. 2021, 50, 703-723. [CrossRef] 